\title{
Implementasi Kriptografi Dan Steganografi Pada Media Gambar Menggunakan Hill Cipher Dan Least Significant Bit (LSB)
}

${ }^{1}$ Wamiliana, ${ }^{2}$ Rico Andrian, dan ${ }^{3}$ Eka Fitri Jayanti

\author{
${ }^{1}$ Jurusan Matematika FMIPA Unila \\ ${ }^{2}$ Jurusan Ilmu Komputer FMIPA Unila \\ ${ }^{3}$ Jurusan Ilmu Komputer FMIPA Unila
}

\begin{abstract}
Cryptography can be used to process message using a specific algorithm that make the message difficult to be understood. After that, steganography is used to hide the message in other forms. This research used modified Hill Cipher and Least Significant Bit (LSB) to build a web based application for sending message and get the original message using an android application. The title and cipher key will be sent automatically by the application to the recipient's email. This application can be used by organizations or companies and use stego cover with file type .jpg and message with file type .txt. The modified Hill Cipher and LSB method can be used to encrypt message, embed it to a image and reveal it to the original message. Our research show that the LSB method has the best possibility to reveal message on image manipulated by changing brightness and contrast if the cover in grayscale, and dominant red and white colours image quality.
\end{abstract}

Keywords : cryptography, steganography, modified Hill Cipher, LSB.

\section{Pendahuluan}

Kriptografi yaitu ilmu dan seni yang digunakan untuk menjaga keamanan pesan ketika pesan dikirim dari suatu tempat ke tempat lain [1] dengan mengolah informasi dengan algoritma tertentu sehingga makna dari informasi tersebut sulit dimengerti. Hill cipher merupakan salah satu algoritma kriptografi simetris yang memiliki kelebihan yaitu ketahanannya terhadap analisis frekuensi [2].

Steganografi digunakan untuk menyembunyikan pesan rahasia di dalam pesan lain sehingga keberadaan pesan rahasia tersebut tidak dapat diketahui [3]. Salah satu metode steganografi adalah metode Least Significant Bit (LSB). Metode LSB dapat menyimpan file teks pada bit yang paling rendah pada pixel gambar sehingga gambar yang telah disisipkan pesan tidak terlihat terjadi perubahan dan tidak menimbulkan kecurigaan [4]. Informasi dapat disembunyikan pada media gambar dengan tipe format file (.jpg).

Penelitian yang telah dilakukan Hasibuan pada tahun 2014 menggunakan Hill Cipher dengan matriks hasil enkripsi dilakukan modulo 256 dan cover object dengan format file (.bmp)[5] lalu dilakukan steganografi dengan metode LSB. Penelitian ini akan membahas tentang sebuah implementasi yang membuat steganografi menggunakan metode Least Significant Bit (LSB) pada media gambar menjadi lebih kuat dan aman dengan melakukan modifikasi algoritma Hill cipher. Sebelumnya pesan dalam format file (.txt) dienkripsi terlebih dahulu lalu disisipkan pada media gambar dalam format file (.jpg) menggunakan aplikasi berbasis web. Aplikasi selanjutnya mengirim email ke penerima yang berisi judul dan kunci agar penerima mendapatkan pesan yang sebenarnya dengan memilih judul dan memasukkan kunci menggunakan aplikasi android. Aplikasi ini akan dapat memberikan perlindungan tambahan dalam pengiriman pesan pada suatu organisasi atau perusahaan.

\section{Metode Penelitian}

Penelitian ini akan melakukan enkripsi dengan algortima Hill Cipher yang telah dimodifikasi pada data teks dengan format file (.txt) menggunakan modulo 128 dan akan melakukan pengurangan matriks yang memiliki nilai seluruh matriks 128 dengan matriks hasil enkripsi. Data teks yang telah disandikan (ciphertext) tersebut disisipkan di dalam citra digital dengan format file (.jpg) menggunakan metode steganografi Least Significant Bit (LSB) pada tiap RGB pixel citra, kemudian data teks dapat diekstraksi dan didekripsi kembali.

Metode penelitian disajikan dalam bentuk diagram alir yang disajikan pada Gambar 1. 


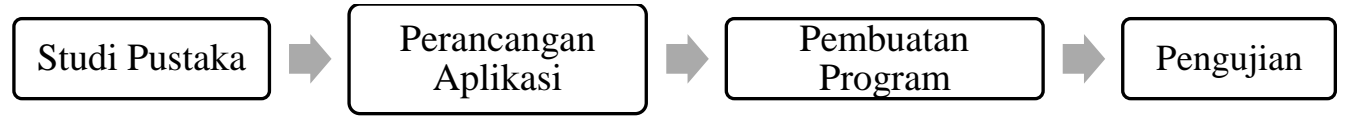

Gambar 1. Metode Penelitian

\subsection{Studi Pustaka}

Tahap studi pustaka dilakukan untuk memahami secara teoritis materi-materi yang berhubungan dengan metode Hill cipher pada data teks dan Least Significant Bit pada media gambar.

\subsection{Perancangan Aplikasi}

Perancangan aplikasi menggunakan use case diagram. Use case diagram pada penelitian ini disajikan pada Gambar 2.

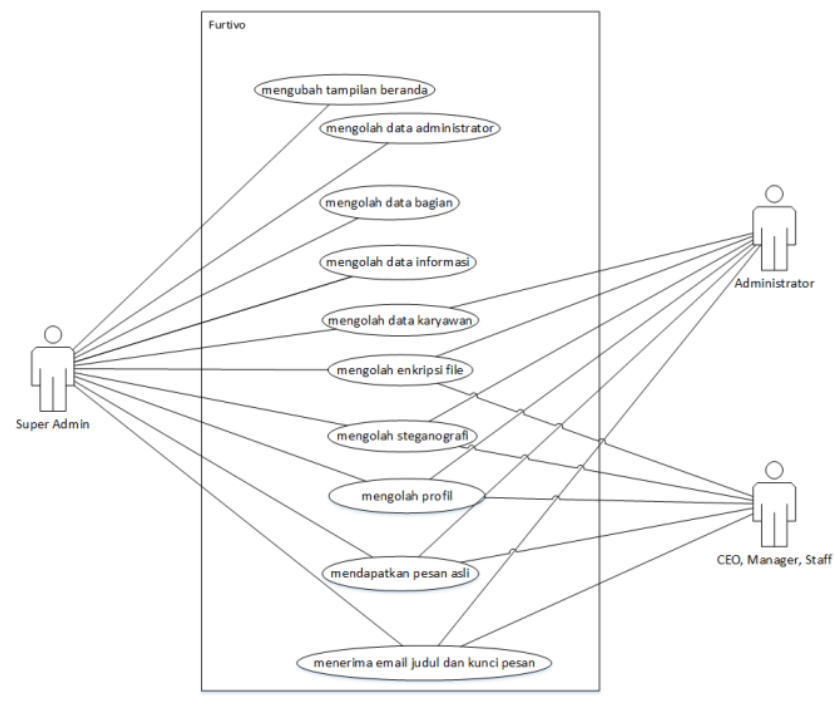

Gambar 2. Use Case Diagram

\subsection{Mengkodekan Aplikasi}

Berkas yang akan disipkan pada media gambar menggunakan format file text (.txt), sedangkan media gambar sebagai penampung digunakan format file (.jpg). Media gambar yang akan diproses untuk mendapatkan kembali file text atau pesan yang asli menggunakan format file (.png). Aplikasi kriptografi dan steganografi berbasis web diimplementasikan menggunakan bahasa pemprograman PHP dan MySQL untuk mengelola database. Aplikasi berbasis android diimplementasikan menggunakan bahasa pemprograman java.

\subsection{Pengujian Aplikasi}

Pengujian yang dilakukan dalam penelitian ini berupa:

1. Pengujian Enkripsi dan Dekripsi

Pengujian enkripsi dilakukan untuk membuktikan proses enkripsi telah dapat mengubah pesan menjadi kalimat lain yang maknanya tidak sama dengan pesan sebenarnya. Pengujian dekripsi dilakukan untuk membuktikan proses dekripsi telah dapat mengembalikan lagi pesan yang makna sebenarnya telah berubah menjadi pesan yang sebenarnya.

2. Pengujian Format File Gambar

Pengujian format file gambar dilakukan untuk membuktikan bahwa gambar dengan format file (.jpg) sebagai input dapat mengeluarkan gambar dengan format file (.png) sebagai output.

3. Pengujian Manipulasi Pada Citra Gambar 
Pengujian manipulasi pada citra gambar terdiri dari manipulasi berupa kecerahan (brightness) dan contrast terhadap gambar. Pengujian manipulasi pada citra gambar tersebut dilakukan untuk membuktikan pengaruh proses manipulasi pada citra gambar terhadap isi pesan.

\section{Hasil dan Pembahasan}

Pengguna yang berperan dalam aplikasi ini yaitu CEO, Super Admin, Administrator, Manager dan Karyawan. Seluruh pengguna dapat mengirimkan pesan yang sebelumnya dienkripsi dan disisipkan ke media gambar kepada seluruh pengguna yang terdaftar melalui halaman pengirim. Pengguna juga dapat memperoleh pesan asli melalui halaman penerima. Ilustrasi deskripsi aplikasi disajikan pada Gambar 2.

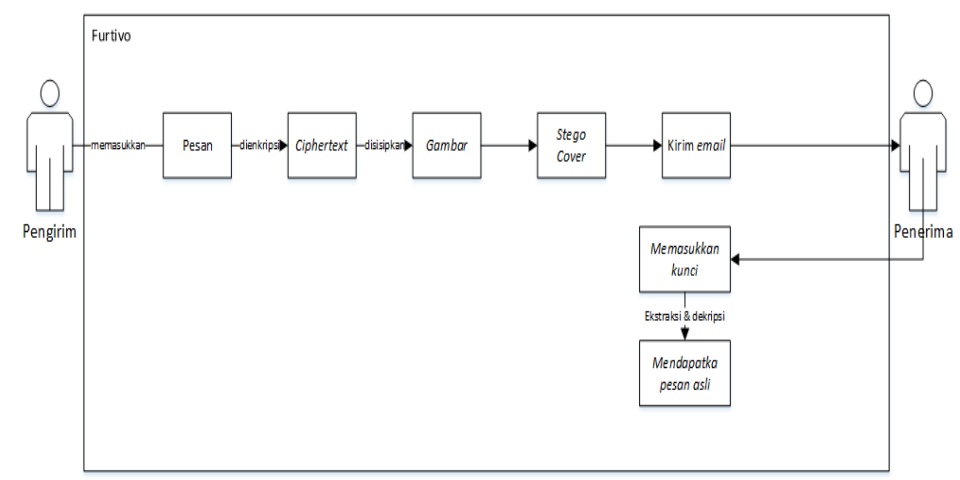

Gambar 2. Ilustrasi Deskripsi Aplikasi

Contoh pesan yang disisipkan disajikan pada Gambar 3.

The Quick Brown Fox Jumps Over the Lazy Dog, .; ${ }^{\prime}[] \backslash<>$ ?: " \{\} $\left.\mid==_{-}^{+}\right)\left(* \&^{\wedge}\right.$ $\% \$ \# ! \sim 1234567890$

Gambar 3. Contoh Pesan Yang Disisipkan

Alasan digunakannya pesan tersebut dikarenakan pesan tersebut mencakup seluruh alfabet dan diikuti dengan seluruh tanda baca serta angka.

\subsection{Pengujian Enkripsi dan Dekripsi}

Pesan telah berubah maknanya (ciphertext) setelah dilakukan enkripsi. Hasil enkripsi (ciphertext) disajikan pada Gambar 4.

$$
\begin{aligned}
& G^{2} ? h ! ! I_{T} V F e . z €
\end{aligned}
$$

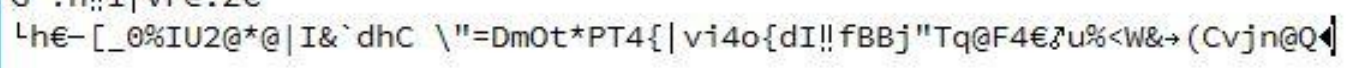

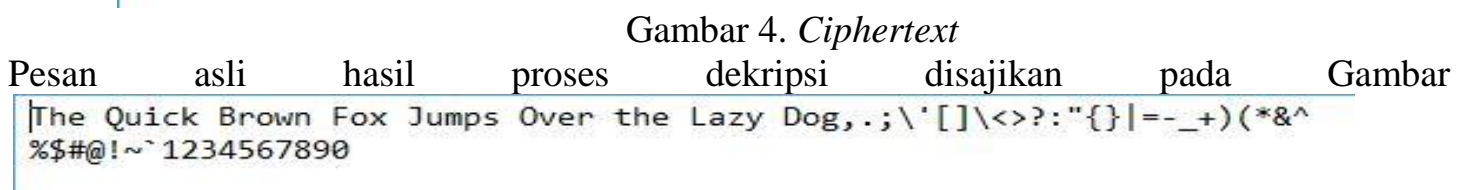

\section{Gambar 5. Pesan Asli Hasil Proses Dekripsi}

\subsection{Pengujian Perubahan Brightness dan Contrast}

Pengujian menggunakan delapan citra gambar dengan format (.jpg) sebagai input atau cover object (media penampung) dengan memberikan perbedaan ukuran interval perubahan brightness (kecerahan) dan contrast pada setiap file gambar stego object. Interval perubahan brightness (kecerahan) adalah 150, -120, -90, -60, - 30, 30, 60, 90, 120 dan 150 dan contrast yaitu -50, -30, 30, 60 dan 90 terhadap stego object. Delapan file gambar (.jpg) disajikan pada Tabel 1. 
(C2017 Ilmu Komputer Unila Publishing Network all right reserve

\begin{tabular}{|c|c|c|c|}
\hline $\begin{array}{c}\text { No } \\
\text { Gambar }\end{array}$ & Gambar (.jpg) & Ukuran Gambar (pixel) & Ukuran Gambar (KB) \\
\hline Gambar 1 & & $1280 \times 800$ & 277 \\
\hline Gambar 2 & & $1625 \times 1080$ & 201 \\
\hline Gambar 3 & & $1020 \times 850$ & 103 \\
\hline Gambar 4 & & $1024 \times 768$ & 76,6 \\
\hline Gambar 5 & & $1440 \times 900$ & 395 \\
\hline Gambar 6 & & $1600 \times 1000$ & 236 \\
\hline Gambar 7 & & $1600 \times 1000$ & 56,9 \\
\hline Gambar 8 & & $1024 \times 768$ & 135 \\
\hline
\end{tabular}

Pesan yang disisipkan (embedded message) dimuat dalam file dengan format (.txt). Contoh pesan (plaintext) disajikan pada Gambar 6.

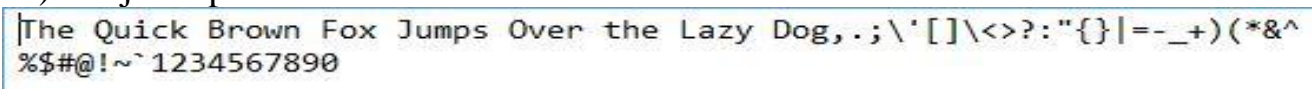

Gambar 6. Plaintext

Delapan stego cover dan stego object dengan besar file dalam bentuk kilobyte (KB) disajikan pada Tabel 2.

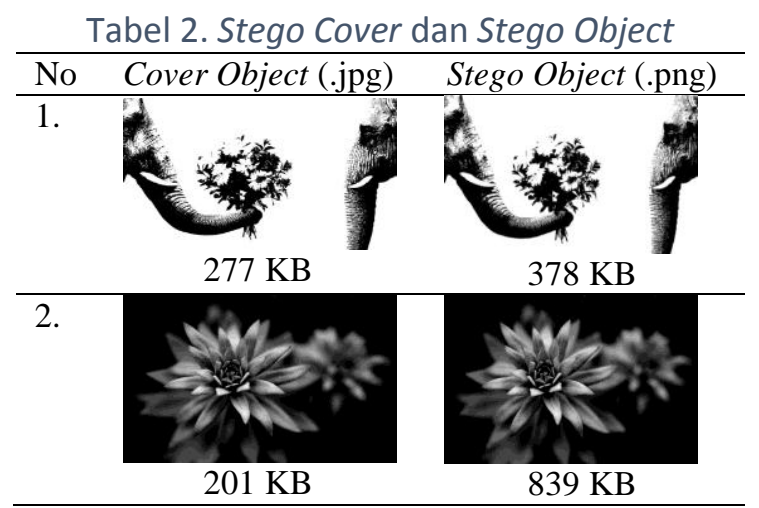




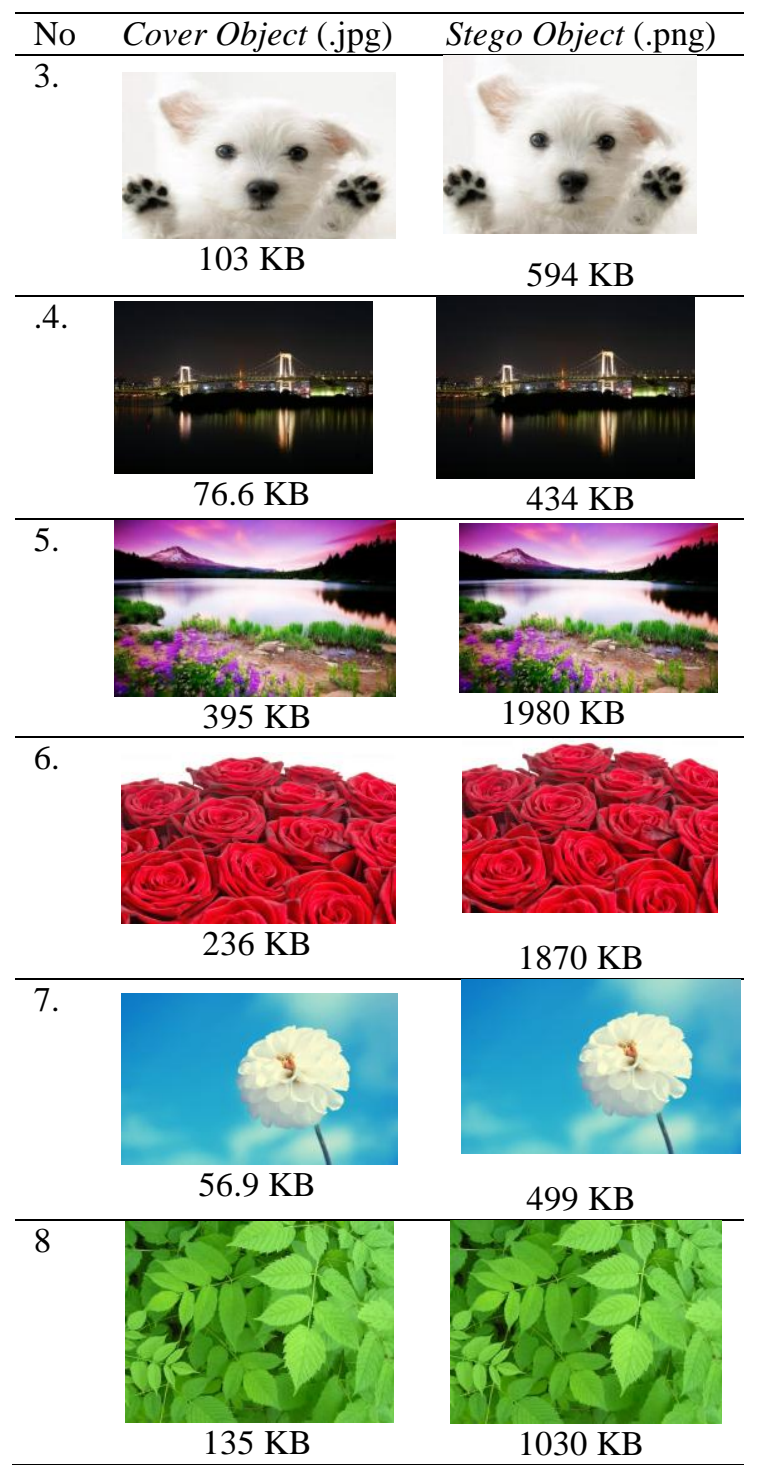

Tabel 2 menunjukkan file gambar dan file stego tidak terlihat perbedaan jika dilihat langsung, namun jika dilihat dari besar gambar kedua file tersebut menunjukkan perbedaan. Perubahan besar file tersebut disebabkan gambar stego sudah berisi file stego sehingga menyebabkan penambahan besar gambar.

\subsubsection{Pengujian Perubahan Brightness}

Pengujian perubahan brightness dilakukan dengan merubah brightness gambar dengan interval -150, 120, -90, -60, -30, 30, 60, 90, 120, 150 pada seluruh stego object. Hasil pengujian dengan perubahan brightness disajikan pada Tabel 3.

Tabel 3. Hasil Pengujian Dengan Perubahan Brightness

\begin{tabular}{|c|c|c|c|c|c|c|c|c|c|c|}
\hline \multirow{2}{*}{ No Gambar } & \multicolumn{10}{|c|}{ Perubahan Brightness } \\
\hline & -150 & -120 & -90 & -60 & -30 & 30 & 60 & 90 & 120 & 150 \\
\hline \multicolumn{11}{|l|}{ Gambar 1} \\
\hline \multicolumn{11}{|l|}{ Gambar 2} \\
\hline \multicolumn{11}{|l|}{ Gambar 3} \\
\hline \multicolumn{11}{|l|}{ Gambar 4} \\
\hline \multicolumn{11}{|l|}{ Gambar 5} \\
\hline Gambar 6 & & & & & & & & & & \\
\hline
\end{tabular}




\begin{tabular}{ccccccccccc}
\hline \multirow{2}{*}{ No Gambar } & \multicolumn{10}{c}{ Perubahan Brightness } \\
\cline { 2 - 9 } & -150 & -120 & -90 & -60 & -30 & 30 & 60 & 90 & 120 & 150 \\
\hline Gambar 8 & & & & & & & & & & \\
\hline \hline
\end{tabular}

berkas tidak kembali $\square$ berkas kembali

Tabel 3 menunjukkan bahwa Gambar 1, 3, 4, 5, 7, dan 8 yang dilakukan manipulasi brightness untuk seluruh interval tidak dapat mengembalikan pesan, namun untuk Gambar 2 dan Gambar 6 dapat mengembalikan sebagian.

Pengujian pada Gambar 2 yang memiliki warna grayscale hasilnya menunjukkan berkas berhasil dikembalikan berada pada interval -60, -30, 30, 60, dan 150. Pengujian pada Gambar 6 yang memiliki warna dominan merah menunjukkan berkas berhasil dikembalikan yaitu pada interval -150, -90 dan 30 walaupun tidak seluruhnya dapat dikembalikan jika dibandingkan dengan gambar lain yang tidak dapat mengembalikan kembali pesan.

\subsubsection{Pengujian Perubahan Contrast}

Pengujian manipulasi contrast pada stego object dilakukan seperti pada pengujian manipulasi brightness pada stego object tapi dengan interval yang berbeda yaitu $-50,-30,30,60$, dan 90. Hasil pengujian manipulasi stego object pada contrast disajikan pada Tabel 4.

Tabel 4. Hasil Pengujian Dengan Perubahan Contrast

\begin{tabular}{|c|c|c|c|c|c|}
\hline \multirow{2}{*}{ Gambar } & \multicolumn{5}{|c|}{ Perubahan Contrast } \\
\hline & -50 & -30 & 30 & 60 & 90 \\
\hline Gambar 1 & & & & & \\
\hline Gambar 2 & & & & & \\
\hline Gambar 3 & & & & & \\
\hline Gambar 4 & & & & & \\
\hline Gambar 5 & & & & & \\
\hline Gambar 6 & & & & & \\
\hline Gambar 7 & & & & & \\
\hline Gambar 8 & & & & & \\
\hline
\end{tabular}

berkas tidak kembali $\square$ berkas kembali

Tabel 4 menunjukkan bahwa Gambar 1, 3, 4, 5 dan 7 yang dilakukan manipulasi contrast untuk seluruh interval tidak dapat mengembalikan pesan kecuali Gambar 2 dan Gambar 6.

Pengujian pada Gambar 2 yang memiliki warna grayscale menunjukkan pesan berhasil dikembalikan berada pada interval interval $-50,-30,30$, dan 60. Pengujian pada Gambar 6 yang memiliki warna dominan merah menunjukkan pesan dapat dikembalikan yaitu pada interval -50, -30, 30 dan 60 jika dibandingkan dengan gambar lain yang hasilnya mengalami pengurangan pesan teks lebih banyak atau bahkan berkas sama sekali tidak kembali. Tabel 8 menunjukkan gambar yang tahan terhadap perubahan contrast adalah gambar dengan warna grayscale dan dominan merah.I

\section{Kesimpulan}

Berdasarkan penelitian yang telah dilakukan, maka dapat ditarik kesimpulan sebagai berikut.

1. Fungsi-fungsi yang ada pada aplikasi telah dapat berjalan dengan baik dan dapat digunakan untuk memberikan perlindungan keamanan tambahan dalam bertukar pesan.

2. Metode Hill Cipher yang dimodifikasi adalah metode yang baik untuk menyamarkan informasi karena pesan asli dengan pesan yang telah dienkripsi terlihat sangat berbeda.

3. Pesan yang disisipkan dapat dikembalikan lagi tanpa mengurangi atau menambah isi pesan.

4. Metode Least Significant Bit (LSB) adalah metode yang mengganti bit-bit terakhir pada pixel gambar sehingga antara stego object dan cover object terlihat sama namun dapat ukuran file bertambah. 
5. Format file gambar (.jpg) dan (.png) cocok untuk digunakan karena setelah proses penyisipan pesan, gambar tidak terlihat berubah.

6. Teknik penyisipan data dengan metode Least Significant Bit (LSB) dengan media gambar tahan terhadap manipulasi berupa perubahan brightness dan contrast, gambar dapat mengembalikan sebagian pesan namun gambar tersebut harus mempunyai nilai warna dominan merah atau greyscale.

\section{Referensi}

[1] Arius, Doni. 2008. Pengantar Kriptografi. Yogyakarta: Graha Ilmu.

[2] Rahman, M. Nordin. A., Abidin, A. F. A., Yusof, Mohd Kamir, Usop, N. S. M.2013.Cryptography: A New Approach of Classical Hill cipher. International Journal of Security and Its Application,7(2), 179-190.

[3] Munir, Rinaldi. 2006. Kriptografi. Bandung: Informatika.

[4] Utomo, T. P. 2011. Steganografi Gambar Dengan Metode Least Significant Bit Untuk Proteksi Komunikasi Pada Media Online. UIN Sunan Gunung Djati Bandung.

[5] Hasibuan, Z. 2014. Perancangan Aplikasi Steganografi dengan Metode LeastSignificant Bit (LSB) untuk Data Terenkripsi dari Algoritma Hill Cipher:Jurnal Informatika, Vol. 6 (3): $150-154$. 